\title{
Toward a Structural Approach to Collection Development
}

\begin{abstract}
A method for developing acquisition priorities based upon scholarly need is discussed, using some of the newer techniques in the area of information science. The structuralist approach requires a method interpreted through the study of behavior and properties of subject literatures. Behavior refers to temporal conditions while properties relate to the organizing principles of class and order. Subject literature behavior and properties are described in this paper through the techniques of citation counting, Bradford's law, and Goffman's indirect method.
\end{abstract}

\begin{abstract}
0 NE OF THE MOST SERIOUS PROBLEMS that exists today in the library is collection development. During the past several decades while money flowed relatively freely, librarians concentrated on building larger facilities, acquiring materials at an exponential rate, and expanding staffs to control the information explosion. The $1960 \mathrm{~s}$ stand as a testimonial to this approach. During this period, the prevailing slogan "the bigger, the better" led one to believe that excellence relates directly to the quantity of volumes that a library holds. Ironically, this slogan has forged the librarian's action into the kiva of materials administration rather than meaningful collection development-
\end{abstract}

James C. Baughman is associate professor, School of Library Science, Simmons College, Boston, Massachusetts. This article is an abridgement of a paper which received one of the 1976 Research Competition awards presented by the ALA Library Research Round Table. This research was supported by a grant from the Simmons College Fund for Research, and the complete paper is to be published in a collected work in the near future. the raison d'être of the library.

Librarians are now beginning to realize that they cannot continue to operate under the assumption that there is no limit to the amount of material that can be acquired, organized, and stored. The production rate of documents is too great and fiscal pressures too acute to allow librarians to retain their former modus operandi. It is time that librarians also realize that it is possible to acquire core quality collections without reaching astronomical figures. ${ }^{1}$ Quality is a relative concept related to relevance, which in the library environment is determined by a measure of effective contact between the collection of knowledge records and the user-not by size. Comprehensiveness in the nineteenth century gave way to the "ideal" of completeness; quantity in the average library in the twentieth century must give way to the "ideal" of quality.

While knowledge records need to be acquired on a continual basis, the important question is: Can they be acquired effectively in terms of knowledge and use? This is the socially relevant question for librarians, and it can be 
answered only through the use of objectively verifiable data based on the premise that acquisitions can be controlled, priorities for collection development established, and funding sought and justified.

Progressing toward the 1980s, librarians will need to experiment with new methods for collection development, including the structuralist approach. The structural approach is discussed and illustrated here as one way to address the collection development problem. The structural approach seeks to find a pattern of relationships, since effective collection building is assumed to rest on identifying a structure. Once the structure is determined, a plan for collection development will quickly emerge.

\section{A Framework For Discussion on Collection Development}

\section{Major Constructs in Collection Development}

Figure 1 graphically illustrates the relationships among the major constructs integral to collection development. These constructs are: (1) use-cluster of demands; (2) knowledge-cluster of disciplines, subjects, topics, and areas of study; and (3) librarianship-cluster of subject literature relationships. Collection development is represented in Segment D of the diagram; it is the intertwining of the concepts of planning, implementation, and evaluation. Collection planning is a design for accumulating documents that belong together as determined by the needs, goals, objectives, and priorities of the library. Collection implementation refers to the process of making documents accessible for use. Collection evaluation involves examining and judging with respect to goals and objectives.

Thus, collection development is a plan which can be implemented and evaluated and may be represented as follows:

$$
\begin{aligned}
& \begin{array}{c}
\text { Collection } \\
\text { planning }
\end{array}+\begin{array}{c}
\text { Collection } \\
\text { implementation }
\end{array} \\
& +\begin{array}{c}
\text { Collection } \\
\text { evaluation }
\end{array}=\begin{array}{c}
\text { COLLECTION } \\
\text { DEVELOPMENT }
\end{array}
\end{aligned}
$$

The enlacing of these concepts into collection development policy leads to a system that is complementary, cyclical, and self-improving.

\section{Use Versus Use Potential}

Librarianship, as a professional, purposeful, goal-directed activity in the area of collection development, means responsibility of decision-making with reference to use and knowledge. (See Figure 1.) In the operational sense, use relates to demands and knowledge relates to needs, or use potential, considering that documents are acquired on a subject basis for use.

There is a difference between demand and need. A user may demand one document when in fact another might better meet his or her need. The need factor is closely associated with the concept of use potential; for if this user were to be introduced to a document which truly met the need, he or she would in fact use that document. The primary constraint here is the document (content) in relation to the user's need. The interplay is among object, content, and use. ${ }^{2}$

The demands that users make on a library collection represent flow from the user to the knowledge base and may be evaluated by user studies. The user study is valuable as a technique for determining use patterns and should be employed as a base for decision-making in the "use" area of collection development. However, user studies have several built-in limitations, two of which are: (1) they establish so-called user groups whose behavior tends to be personal, introspective, and variant; and (2) they measure only the materials currently held in a given library whose subject collections may range from poor to excellent. 


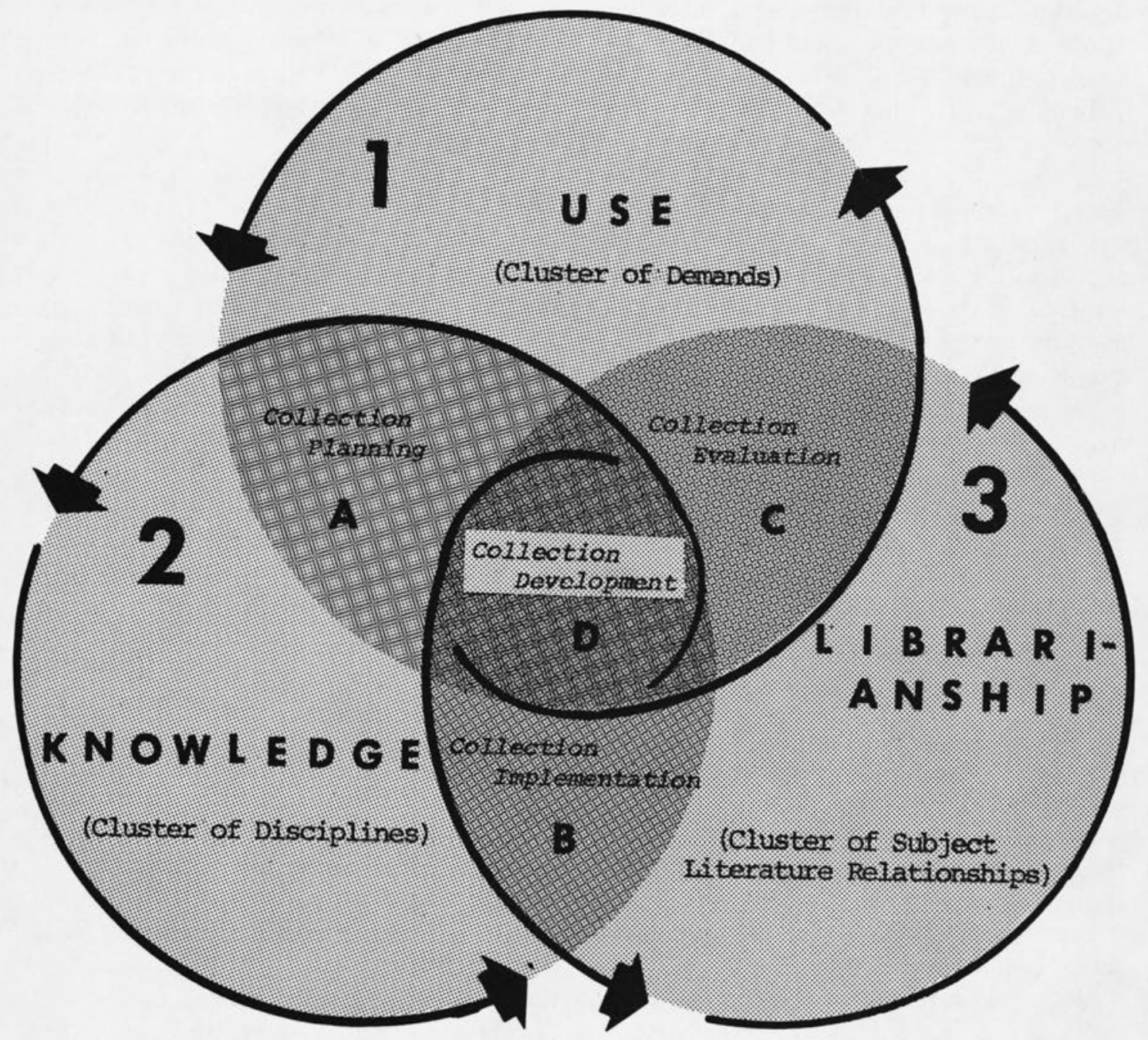

Fig. 1

Collection Development: A Structural Approach

This self-limiting method of determining collection development policy does reveal special interests singular to the clientele of an individual library, but it fails to improve the quality of a collection in terms of new acquisitions of value. Depending solely upon the user study for collection development, decision-making usually places the librarian behind the eight ball, since demands are observable only after-thefact. One can run to catch up, but it might be better to be running to keep ahead!

When library collection policy is for- mulated with an eye to the structure of subject literatures, the librarian may be in a better position to cope with the voluminous production of knowledge records from which he or she must isolate and secure those documents that have use potential. The librarian has the responsibility of building collections that include items with inherent value, representing a potential need for library users. Here the flow is from the knowledge base to the user. How often has the librarian heard the patron say: "I had this in mind, but can you recommend something better?" Patrons in this 
situation know that they need information but are not quite sure of their information needs.

The interplay between demand and need must receive thoughtful attention for effective collection development. The question is: How far in each direction should acquisition policy go in order to build the "best" library collection for users? The proper balance between use and use potential is not precise, nor can it realistically be. The relationship, never having been clearly defined, represents an existential dilemma for the librarian. This is why it is important for the librarian to be aware of the cluster of demands and the cluster of disciplines within the framework of collection development.

\section{The Structure of SubJect Literatures}

Since librarians build library collections for use and use potential (need), their decision-making should take into account the structure of subject literatures. In collection development the subject (discipline) is the superordinate constraint, since users use documents in terms of a subject and its literature.

Rational inquiry into problem areas produces a body of knowledge that is organized into a subject field. This subject matter is publicly shared through a literature, which records, displays, stores, and transmits pertinent states of knowledge at a given point in time. From this rationale one can make the assumption that a state of knowledge is reflected in its literature. This relationship is established through logical inference, i.e., if one ascertains the structure of a literature, then it may be assumed that a structure has been determined on an indirect basis for a knowledge area, since the literature contains pertinent states of knowledge. ${ }^{3}$

The overriding viewpoint here is that subject literature structure, a way of seeking relationships, will provide un- derstanding of the literature's behavior and properties-not its intellectual content per se. Thus, the structural approach to subject literatures involves the study of the behavior and properties of a subject literature.

The "behavior," i.e., a characteristic way of acting, may be interpreted with reference to "literature statics" (a point in time) and "literature dynamics" (a period of time). Literature statics may be investigated through several of the newer information science techniques, now referred to as bibliometrics (the measurement of bibliography) in their specific instance of use. One of these techniques is Bradford's law, ${ }^{4}$ the application of which is discussed under "Core Publishers" below.

The "properties" of a subject literature refer to (1) class and (2) order To understand knowledge it must be organized (class) and sequenced (order). To be useful, knowledge must be organized. Of course, no system of organization can be absolutely successful, but without it no system can approach success. An innovative method for organizing and sequencing knowledge is suggested by Goffman. ${ }^{5}$ The organizational aspect (class) of this method is discussed under "Associated Subjects" below.

Investigation into the behavior and properties of a subject literature may be facilitated by dividing the literature situation into parameters. This study is a continuation of the author's previous work in sociology. The parameters of time and language in relation to sociology literature are discussed in a previous study. ${ }^{6}$ This paper presents further discussion of the parameters of (1) associated subjects and (2) form (objects) and introduces (3) publishers.

\section{Associated Subjects-Establishing Subject Relationships}

The grist of the librarian's mill is the subject; thus, a major concern should 
be to determine the inter- and multirelationships among subject areas.

Although the interdependence among the various disciplines within the social sciences has long been recognized as a condition necessary to their progress, each discipline has traditionally been treated as a separate entity. In the past several decades, there has been a shift in emphasis in the social sciences from one of isolation to one of merging information to produce patterns of knowledge that overlap. More and more academic programs are reorganizing their course offerings along new interand multidisciplinary lines. Such curricula changes will need to be reflected in the library collection.

The beginning point should be the identification of subject relationships. Identifying overlapping subject areas indicates which subject areas are in communication. This communication needs to be determined since empirical relationships among associated subjects lay the foundation for present-day library collection development. Without an understanding of subject relationships, the librarian is lost in a sea of disjoint documents representing content from which selections must be made. Determining subject relationships is important, not only for the physical organization of materials, but also for the intellectual organization of knowledge for collection development purposes.

Subject relationships may be determined on a macro or micro levelmacro referring to general areas and micro to specific topics. In approaching both the macro and micro levels, the procedure used in this study to establish subject relationships follows Goffman's indirect method. The Goffman method differentiates between the relevant and the not-so-relevant subject areas by investigating the overlap of subject coverage in individual journals.

For the author's investigation into subject relationships in the social sci- ences on the macro level, the data base, used in connection with the Goffman model, was Volume I (1974-75) of the Social Sciences Index (SSI). ${ }^{7}$

In volume 1 of SSI there were 4,995 subject headings with 30,673 entries. Since the concern here is with macro relationships, only the most productive subject areas-those headings with eleven or more unique entries-were included for this part of the study. The 309 subject headings with eleven or more unique entries were grouped into sixty-one $\mathrm{Li}$ brary of Congress classification areas in order to condense the subject headings into systematized groupings that could be studied for interrelationships on the macro level.

Goffman's indirect method was then applied to the sixty-one subject groupings. The results of this procedure indicate that there is one major class consisting of eleven strongly interrelated subjects. By further applying the LC classification system, the eleven subject areas may be condensed into six social science disciplines. These disciplines, presented in Figure 2, may be said to be interrelated since there are strong communication links among them as determined by the Goffman model.

The significance of the macro subject relationships is that with these findings librarians may be alerted to the spectrum of subjects that need to be considered together in building library collections. The findings suggest that building strong central collections in the social sciences may be more advisable than departmentalizing, since developing departmental libraries would require extensive duplication of informational materials with resulting higher expenditures.

The librarian needs to consider subject relationships not only on the macro but also on the micro level. If a user is interested in a specific topic (micro level), such as "human ecology," he or she may be expected to become interest- 


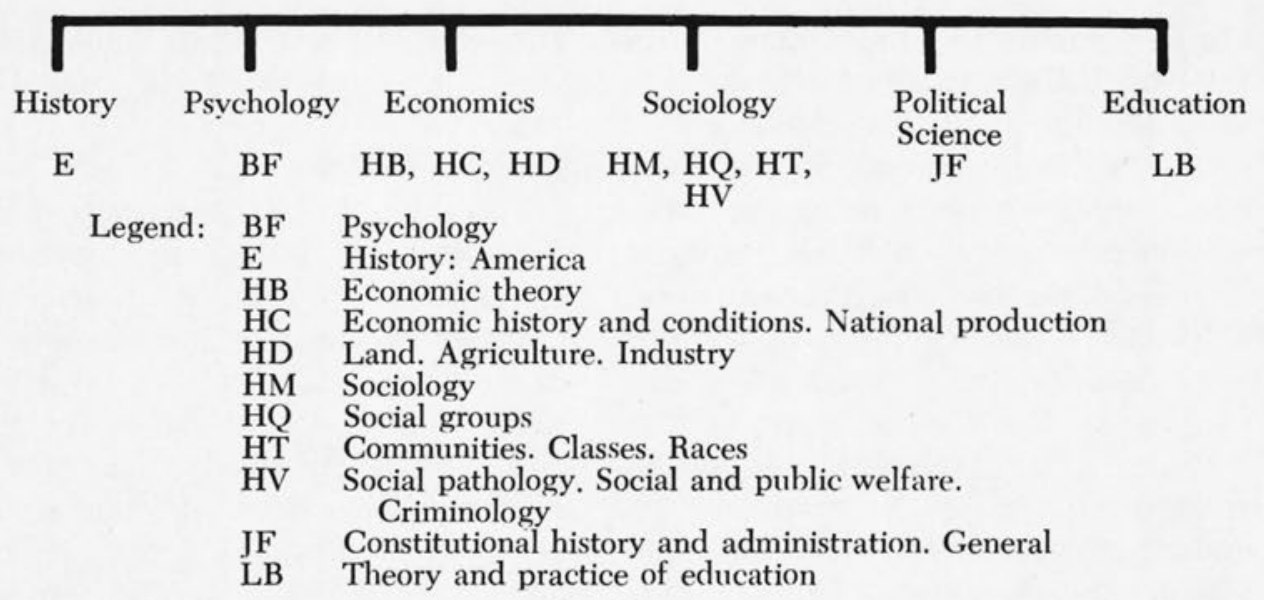

Fig. 2

Social Science Disciplines in Communication

ed in related topics within the content structure of the general subject of sociology. The question then becomes: "If a user is studying 'human ecology,' what other topics would most likely be of interest because of their close alliance with the topic 'human ecology'?"

To search for solutions in this problem area, the author conducted an investigation into the interrelationships of subject headings on the micro level within the discipline of sociology. In this case, all subject headings (including "see also" references) under the general heading "Sociology" in Volume 1 of SSI (1974-75) constituted the data base. It was not necessary to group these subject headings since the interest here is in micro relationships. Therefore, all eighty subject headings were related, without interpolation, by Goffman's model. Eleven distinct classes emerged. One of these classes, for example, shows the topic "human ecology" (primarily concerned with a population's collective interaction with its environment) to be in communication with (1) cities and youth, (2) population, (3) urban sociology, and (4) urbanization.

\section{Form}

The study of subject literatures can impart information through the parameter of form. The acquisitions officer needs to know whether to concentrate more heavily on journals or on books in a given subject area. In order to determine if there is a reliance on serial or nonserial materials in the social sciences in general, a study of five selected major social science journals was conducted. All citations from the complete issues of these journals for the year 1974 were tabulated by percentage of serial and nonserial citations. The results are presented in Table 1.

TABLE 1

Form of the Literature Citations FROM SELECTED Major Social SCIENCE Journals

\begin{tabular}{lll}
\hline \hline \multicolumn{1}{c}{ Journal } & $\begin{array}{c}\text { Serial } \\
\text { Percent }\end{array}$ & $\begin{array}{c}\text { Nonserial } \\
\text { Percent }\end{array}$ \\
\hline American Anthropologist & 42.93 & 57.07 \\
American Economic Review & 59.02 & 40.97 \\
American Historical Review & 23.3 & 77.6 \\
$\begin{array}{c}\text { American Political Science } \\
\text { Review }\end{array}$ & 34.59 & 65.36 \\
American Sociological Review & 44.41 & 55.59 \\
\hline
\end{tabular}

Note: The author acknowledges the helpfulness of several of his students in preparing the data for this table.

This information clearly illustrates that current social science scholars rely, as depicted in the citation patterns of these major disciplinary journals, upon nonserial literature for a major portion of their support material. It may be conjectured that within the parameter of form the literature of the social sci- 
ences may behave differently from the literature of the natural sciences. The natural science literature consists almost exclusively of papers published in journals. ${ }^{8}$ This would seem to have significance in that it may be more necessary to build stronger monographic collections in the social sciences than in the natural sciences.

\section{Core Publishers}

Librarians have long sensed the need to follow selected publishers' catalogs in subject areas of interest to the library's users. This procedure is automatic and is considered fundamental to successful collection development. The operating assumption here is that a selected group of publishers accounts for a large percentage of the books being published on a given subject. This everyday logic-in-use may be examined on a formal basis by using Bradford's law. ${ }^{9}$ Originally formulated with respect to journal literature, this law, in general, states that a small percentage of journals accounts for a large percentage of significant articles in a specific subject area.

Worthen investigated the Bradford law with respect to monographs in a specific medical subject area and determined that it applied..$^{10}$ Since the social science literature relies more heavily on nonserial literature than does the natural science literature, it is important to determine the applicability of the Bradford law to social science monographic literature.

To test Bradford's law in relation to nonserial literature in the social sciences, the discipline of sociology was specifically investigated. The data base for this experimental test was a random sample of 495 monographs representing 10 percent of the 4,954 independent bibliographic units isolated through a citation count of 446 journal articles from 71 different journals in the discipline of sociology. ${ }^{11}$ The Bradford law was applied to the random sample of monographs, the results reported in Table 2.

TABLE 2

Maximal Divisions of Monographs PUBLISHERS

\begin{tabular}{|c|c|c|c|}
\hline Zone & $\begin{array}{l}\text { Number of } \\
\text { Monographs }\end{array}$ & $\begin{array}{l}\text { Number of } \\
\text { Publishers }\end{array}$ & $\begin{array}{c}\text { Bradford } \\
\text { Multiplier }(b)\end{array}$ \\
\hline 1 & 46 & 2 & \\
\hline 2 & 48 & 3 & 1.5 \\
\hline & 57 & 4 & 1.3 \\
\hline 4 & 53 & 5 & 1.3 \\
\hline 5 & 46 & 7 & 1.4 \\
\hline 6 & 48 & 10 & 1.4 \\
\hline 7 & 48 & 16 & 1.6 \\
\hline 8 & 46 & 23 & 1.4 \\
\hline 9 & 49 & 42 & 1.8 \\
\hline 10 & 54 & 54 & 1.3 \\
\hline Total & $\ldots \overline{495}$ & $\overline{166}$ & $\overline{1.5^{\circ}}$ \\
\hline
\end{tabular}

- Average

The Bradford multiplier $(b)$ in Table 2 is an empirical rendition of the Bradford series $\left(I: n: n^{2} \ldots\right)$ where the ratio $(n)$ is the Bradford multiplier $(b)$. This indicates that approximately the same number of documents is produced by a number of publishers which increases from zone to zone such that the ratio between the number of publishers in the second and first zones is the same as between the third and second, fourth and third, etc.

The minimal nucleus of publishers (Zone 1) consists of two publishers representing forty-six monographs, followed by three publishers representing forty-eight titles (Zone 2), four publishers with fifty-seven titles (Zone 3 ), etc. Successive zones of publishers publishing about the same number of monographs form the approximate geometric series $1:(1.5):(1.5)^{2}: \ldots$ : $(1.5)^{9}$. The results also show that half of the monographs were accounted for by only twenty-one publishers or 12.6 percent of the total number of publishers in the sample.

Thus, it may be stated that the literature of sociology exhibits a Bradfordian distribution when the publishers are ranked by the productivity of cited 
monographs. The most productive publishers on the subject tend also to publish the monographs that are most frequently cited. The commonsense notion of using core selected publishers' catalogs to assist in building collections is empirically verified.

\section{Conclusion}

The basic underlying assumption of this study is that the structure of subject literatures will provide the librarian with a fruitful guide to collection development. Collection development consists of: (1) collection planning (assessing needs, setting goals, and establishing priorities); (2) collection implementation (action, communication, scheduling, disseminating, etc.); and (3) collection evaluation (assessing and judging with respect to goals and objectives).

The structure of subjects, as well as the structure of subject literatures, is determined by concepts and generalizations intertwining to form the foundation for reflective inquiry. The concepts employed in this investigation center on the behavior and properties of subject literatures. Thus, the structuralist in the subject literature situation seeks out patterns and relationships without explicit reference to the intellectual content of the literature units per se; i.e., the structuralist's overriding concern is with the understanding of literature forms and processes, rather than the literature's scholarly content.

Some of the major conclusions that may be drawn from this study are as follows:

1. Subject relationships, which are fundamental to the intellectual organization of knowledge for collection development, may be determined by studying the communication links that exist among associated subjects.

2. Communication links may be determined on a macro (disciplinary) and a micro (subject, topics, etc.) level.

3. Social science scholars cite nonserial literature more frequently than serial literature; thus, collection development officers need to consider, in particular, monographic literature units in social science collections.

4. The behavior of literature units in publishing, as determined by the citations of scholars in journal articles, conforms to the Bradford law, which means that a few publishers account for the bulk of the cited monographs. Half the cited books were accounted for by only 12.6 percent of the publishers.

\section{REFERENCES}

1. James C. Baughman, "The Library Ecology Problem," in Karl Nyren, ed., LJ Special Reports \#1: Library Space Planning (New York: Library Journal, 1976), p.45-47.

2. Conrad H. Rawski, "Subject Literatures and Librarianship," in Larry Earl Bone, ed., Library School Teaching Methods: Courses in the Selection of Adult Materials (Urbana, Ill.: Univ. of Illinois, 1969), p.97-103.

3. Conrad H. Rawski, "The Scientific Study of Subject Literatures," mimeographed (Cleveland, Ohio: Case Western Reserve University, School of Library Science, 1976), p.1.

4. Samuel C. Bradford, Documentation, 2d ed. (London: Crosby Lockwood \& Son, Ltd., 1953), p.154.
5. William Goffman, "An Indirect Method of Information Retrieval," Information Storage and Retrieval 4:361-73 (Dec. 1968).

6. James C. Baughman, "A Structural Analysis of the Literature of Sociology," Library Quarterly 44:293-308 (Oct. 1974).

7. See Social Sciences Index, 1974-1975, vol. 1 (New York: H. W. Wilson, 1975).

8. Rolland E. Stevens, Characteristics of Subject Literature, ACRL Monograph no. 6 (Chicago: American Library Assn., 1953), p.17.

9. Bradford, Documentation, p.154.

10. Dennis B. Worthen, "The Application of Bradford's Law to Monographs," Journal of Documentation 31:19-25 (March 1975).

11. Baughman, “A Structural Analysis," p.296. 